\title{
Numerical Simulation of Nitrogen Foam Injection to Control Water Cresting by Bilateral Horizontal Well in Bottom Water Reservoir
}

\author{
Liu Yong-Ge, Liu Hui-Qing and Pang Zhan-Xi
}

\author{
MOE Key Laboratory of Petroleum Engineering, China University of Petroleum, Beijing, 102249, China
}

\begin{abstract}
By numerical simulation, a bilateral horizontal well is placed in a crude oil reservoir with bottom water. The upper branch which is located near the top of the reservoir is for producing and the lower branch which is located near the oil water contract is for nitrogen foam injecting. Packers are used to control the alternation between productions and injections. When water cut of the upper branch reaches a certain value, this branch is shut and nitrogen foam is injected into the lower branch. After two days' soaking, the upper branch is opened to produce again. This process can be repeated for several times along with the reservoir development. The main mechanisms of this development style are analyzed, and different injecting methods including injecting foam in the lower branch (IFLB), injecting foam in the upper branch (IFUB), and injecting nitrogen gas in the lower branch (INLB) are contrasted. The effect of reservoir heterogeneity on the performance of IFLB is also considered. Various stochastic realizations with different shale contents and correlation lengths are established by sequential indicator simulation method. In order to explain the large variations occurring in the realizations with same shale content and correlation length, the definition 'below well region' (BWR) is put forward and two groups of models with different BWR are built to simulate the performance of IFLB. As expected, the geological condition of BWR has a great effect on the performance of IFLB. If the shale content of BWR is low, good performance can be obtained with any combination of shale content and correlation length for the remaining region. On the contrary, if shale content and continuity of BWR are high, the performance of IFLB will significantly decrease.
\end{abstract}

Keywords: Nitrogen foam, bottom water, crude oil reservoir, bilateral horizontal well, cresting control, sequential indicator simulation.

\section{INTRODUCTION}

For a given rate, horizontal wells require a lower pressure drawdown compared to conventional vertical wells. Therefore, in the development of bottom water reservoirs, horizontal wells have been widely used to enhance oil production in the world [1-7]. Some field implementations have shown that the use of horizontal wells can reduce coning problems and get more oil production in bottom water reservoirs $[8,9]$. Many researchers also think that there is a critical rate below which the flat surface of water-oil contact will not deform when using horizontal wells to develop bottom water reservoirs $[10,11]$. However, in practice, the practical production rate of a horizontal well is often higher than critical production rate due to economic consideration.

The invasion of bottom water could lead to a sharp increase of water cut and shorten the life of production wells greatly. Presence of impermeable barriers could influence the mechanism of water invasion greatly. These barriers give more resistance to water invasion, so the rise speed of water cut will slow down and the well performance with respect to oil production could be much better. Many publications related to the effect of impermeable barriers on the development of bottom water reservoirs are available [12-14].

*Address correspondence to this author at the China University of Petroleum (Beijing), Changping district, Beijing City, China; Tel: +86.15210727091; Fax: +86.10.8973.3511;

E-mails: 2011312039@student.cup.edu.cn,yg.leo@foxmail.com
Besides natural barriers, many researchers have devoted themselves in the technology about how to delay the coning/cresting of water by artificial methods. Barnes [15] in the early 1960s has first suggested that using a viscous water slug can improve the performance of wells in a partially water-invaded reservoir. He pointed out that if the viscosity of injected water was greater than $1.0 \mathrm{cp}$, the flood life could be shortened and the ultimate oil recovery would increase. Islam and Ali [16] carried out a comprehensive experimental analysis of the water plugging ability of various agents including polymer slugs, emulsions, air, biopolymer gels and foam on the development of bottom water reservoirs. In their study, emulsion gave a better performance than other chemical agents.

Although many experiments and simulations have been conducted on the development of bottom water reservoirs, most of these researches took vertical wells as injectors. Therefore, the occurrence state of the injected blocking agent will be quite different from that of the agent injected by horizontal wells, i.e. the agents injected by vertical wells can't spread out in the same fashion in bottom water reservoir as compared to that by horizontal wells. Also, the effects of reservoir heterogeneity on the performance of blocking agents in bottom water reservoirs are rarely considered.

\section{THEORY OF CRESTING CONTROL BY DOUBLE HORIZONTAL WELLS USING NITROGEN FOAM}

Fig. (1) provides a schematic plot of this development style. When the production rate of the upper production 
branch exceeds the critical rate, the flat surface of water-oil contact will deform, i.e., water cresting will happen. When water cut of the production branch reaches a certain value, this branch is shut and nitrogen foam is injected into the lower branch. After soaking, when the upper producing branch is open again, the injected nitrogen foam will provide a great resistance to the invasion water which will lead to a lower water cut and higher oil production rate. Detailed mechanisms of this style include:

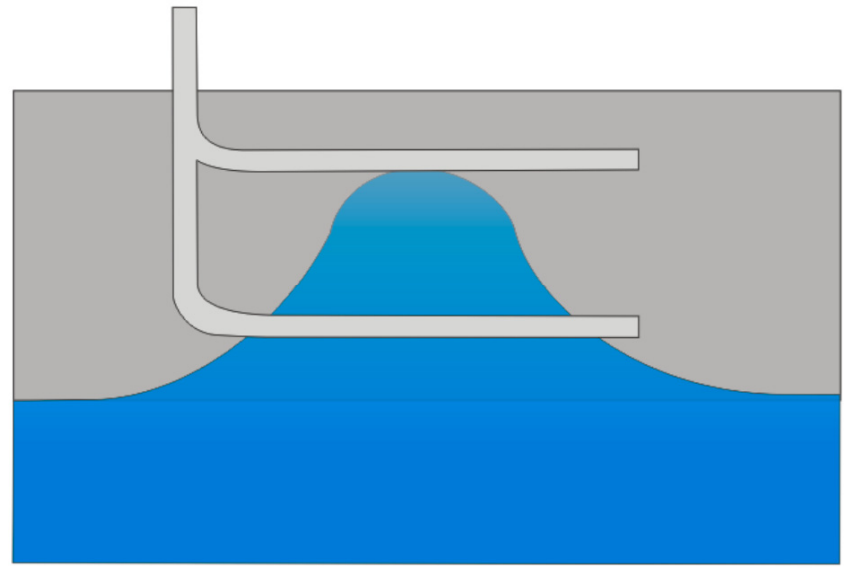

Fig. (1). Schematic of the development of bottom water reservoir by bilateral horizontal well.

1. At the bottom of the oil zone, the injected nitrogen foam will lead to a sharp pressure rise near the injection branch and the water cresting profile will move down under this high pressure.

2. Nitrogen gas is insoluble in water and slightly soluble in oil and has a good expansibility (about three times of that for $\mathrm{CO}_{2}$ ). So at the production period, on one hand, the expansion of nitrogen can supplement the pressure drawdown caused by production so that water cresting can be postponed; on the other hand, more oil can be flooded to the production branch by nitrogen. More significantly, the apparent viscosity of nitrogen foam is quite high. So after injection, the invasion water shows a trend of bypassing the foam area, which will improve the sweep efficiency of bottom water flooding.

3. The foaming agent injected is a kind of surfactant with strong activity. It can lower the interfacial tension significantly and alter the wettability of the rock to some extent, so a part of oil which is in bond state at water flooding process can be displaced after the injection of foam. At the same time, oil has the property of accelerating foam decay so the lower oil saturation caused by surfactant will lead to a better stability of the subsequent injected foam. This will enhance the blocking ability of foam to defend against the following bottom water invasion.

4. Along with the decay of foam, nitrogen gas will rise to the top of the reservoir due to gravity segregation. These gases will create a secondary gas cap at the top of the reservoir that can provide elastic energy to supplement the pressure drawdown caused by production and displace oil in the upper zone to the production branch.
5. Regarding to heterogeneous reservoirs, bottom water will flow to the production branch along high permeability channels leaving much oil unswept in the reservoir. When injected, foam will go into the high permeability channels first and this part of foam will be more stable due to low oil saturations of these channels. So when producing, the following invasion water will encounter a great resistance in these high permeability channels and flow to other low permeability channels instead. Thus the sweep efficiency of heterogeneous reservoirs will be improved.

\section{COMPARISON OF DIFFERENT DEVELOPMENT STYLES ON HOMOGENEOUS MODELS}

\subsection{Reservoir Description and Model Building}

STARS simulator developed by Computer Modeling Group (CMG) Ltd. is used in this simulation study. Relevant model, reservoir and fluid properties which are listed in Table $\mathbf{1}$ are all taking the actual data of a block in Shengli oil field as references.

It is a $32 \times 15 \times 28$ grid block model. In order to simulate vertical water invasion and the performance of nitrogen foam accurately, grid block size in $\mathrm{z}$ direction is set to $1 \mathrm{~m}$ compared to $20 \mathrm{~m}$ in $\mathrm{x}$ and $\mathrm{y}$ direction. Thicknesses of oil zone and water zone are set to $20 \mathrm{~m}$ and $8 \mathrm{~m}$, respectively, and an infinite aquifer simulated by Carter-Tracy method is connected to the bottom of the water zone. Both horizontal branches are $300 \mathrm{~m}$ long. The upper one is located $4.5 \mathrm{~m}$ below the top of the reservoir and the lower one is located $17.5 \mathrm{~m}$ below the top, which means separation distance between it and the water/oil contact is only $2.5 \mathrm{~m}$. Gas liquid ratio and mass fraction of surfactant solution in this study are set to $1: 1$ and $0.5 \%$, respectively, according to the optimized results of previous physical experiments [17]. The mechanism model considering foam generation, coalescence, and oil acceleration on foam decay by adding a component lamella is chosen to simulate this process precisely. In-situ generation mode is taken considering that poor injectivity may be caused by preformed foam injection mode.

In order to choose the best development style, four different approaches including injecting nitrogen foam in the lower branch (IFLB), injecting nitrogen foam in the upper branch (IFUB), injecting nitrogen gas in the lower branch (INLB) and producing only by bottom water flooding (BWF) are compared. All stimulation treatments are performed after 400 days following the production i.e. water cut of the production branch reaches $80 \%$. Agents are injected for 20 days and after 2 days' soaking the upper production branch is open to produce for 500 days. This cycle is repeated for 4 times and the terminated time in simulation is $2480 \mathrm{~d}$. For each cycle's foam injection, the injection speeds of surfactant and nitrogen gas are set to $200 \mathrm{~m}^{3} / \mathrm{d}$ and $17600 \mathrm{~m}^{3} / \mathrm{d}$ respectively according to the fixed gas liquid ratio $1: 1$. For nitrogen injection only, the injection speed is set to $35200 \mathrm{~m}^{3} / \mathrm{d}$ so that in all cases total injected volumes in reservoir condition are the same.

\subsection{Simulation Results and Analysis}

Cumulative oil productions of four development stylesshown in Fig. (2) are contrasted. From this figure we 
Table 1. Numerical Simulation Parameters Used in this Study

\begin{tabular}{|c|c|c|c|}
\hline Property & Value & Property & Value \\
\hline \hline Total number of blocks & 13440 & Oil saturation & 0.65 \\
\hline Length & $32 * 20 \mathrm{~m}$ & Water saturation & $1,000 \mathrm{~m}$ \\
\hline Width & $15 * 20 \mathrm{~m}$ & Grid top depth & $1,020 \mathrm{~m}$ \\
\hline Height & $28^{*} 1 \mathrm{~m}$ & Water/oil contact & $20 \mathrm{~m}$ \\
\hline Horizontal permeability & $1,500 \mathrm{mD}$ & Pay zone thickness & Carter-Tracy \\
\hline Vertical permeability & $150 \mathrm{mD}$ & Aquifer type & $67 \mathrm{cp}$ \\
\hline Porosity & 0.3 & Oil viscosity(R.C.) & $943.5 \mathrm{~kg} / \mathrm{m}^{3}$ \\
\hline Initial Temperature & $60^{\circ} \mathrm{C}$ & Oil density & 1 \\
\hline Initial Pressure & $10,000 \mathrm{Kpa}$ & Net gross ratio & \\
\hline
\end{tabular}

can conclude that different injection styles can lead to distinct development effects. For IFLB, cumulative oil production increased by a big margin after four cycles' of foam injection. While for IFUB and INLB, no obvious effect was got. Detailed simulation analyses are as follows:

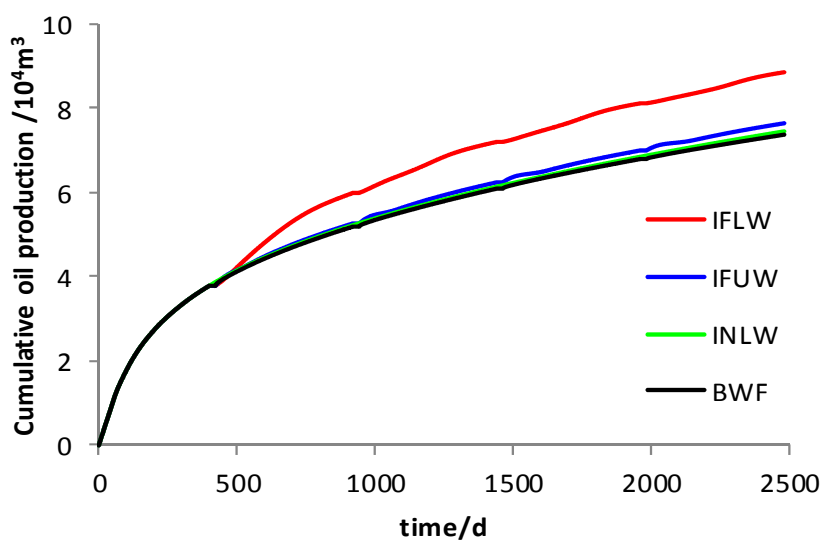

Fig. (2). Comparison of cumulative oil productions for different development styles.

1. Fig. (3) compares water influx rate distributions at $450 \mathrm{~d}$ for BWF and IFLB. The unit of water influx rate is set to $\mathrm{m}^{3} / \mathrm{d}$. As can be seen in this figure, for IFLB, after foam injection, water invasion is

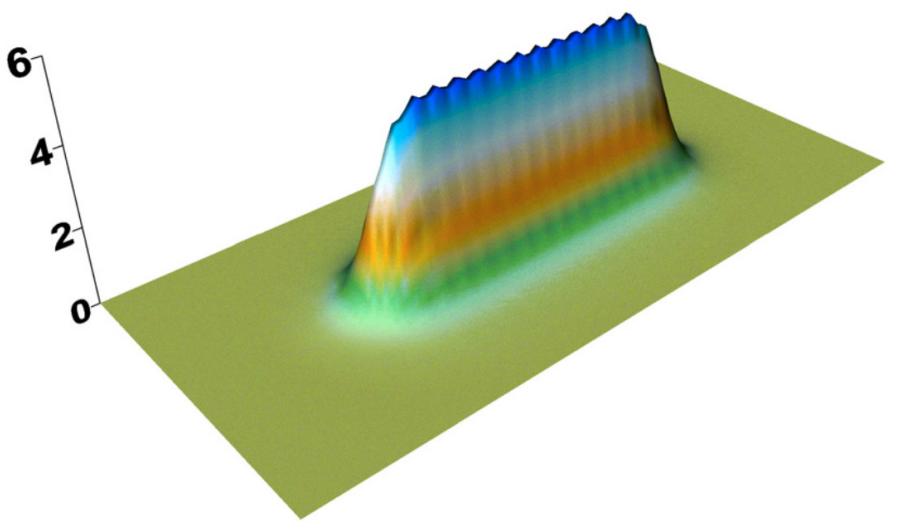

(a) suppressed significantly and foam forms strong blockage around the injection well, which can force the following water to bypass the foam zone. This phenomenon is quite similar with the simulation results obtained by Zhao et al. [12]. In their simulations, when barrier exists, invasion was forced sideways and bypassed the barrier to form secondary cones along the barrier edges. While the major difference of these two results consists in the properties of barriers, i.e. foam blocks water invasion zone temporarily compared to the permanent blockage of impermeable barriers.

Fig. (4) shows the contribution of secondary gas cap on the enhancement of oil recovery. Upper limits of both color legends are set to 0.649 considering that the original oil saturation is 0.65 . As illustrated in this figure, the gas cap displaced more oil in the upper unperforated layers by IFLB.

(2) For IFUB, no obvious effect is obtained. The main reason is that the injected foams are all surrounding the upper branch and high oil saturation of the near branch region can accelerate foam decay greatly. Meanwhile, the near branch region has a bigger pressure gradient so apparent viscosity of foam will decrease sharply due to the shear dilute rheological characteristic property. When the upper branch is

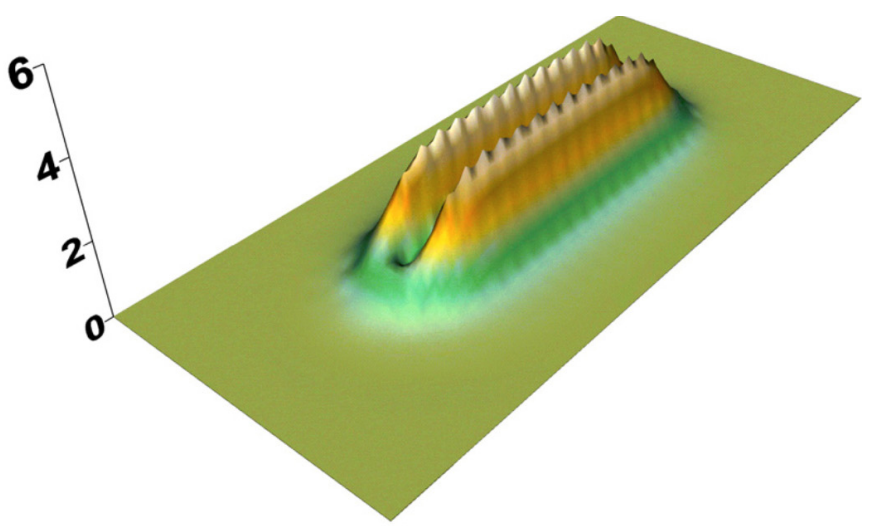

(b)

Fig. (3). Comparison of Water influx rate distributions at 450d by (a) BWF and (b) IFLB. 


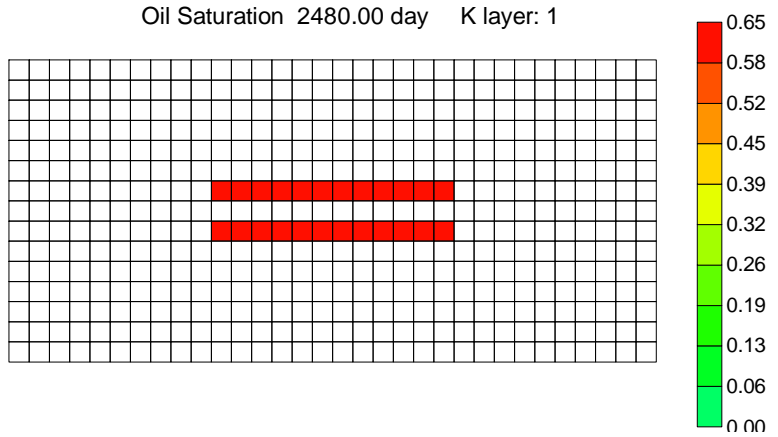

(a)

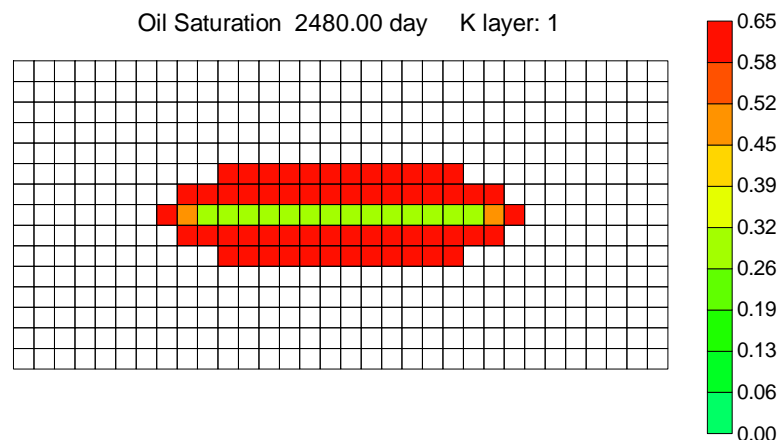

(b)

Fig. (4). Oil saturation comparison of layer 1 at $2480 \mathrm{~d}$ by (a) BWF (b) IFLB.

open again, gas released by foam decay will be produced from this branch quickly, which will lead to a failed anti-water-cresting operation. Fig. (5) which shows the comparisons of gas saturations for IFUB and IFLB gives strong support to the above analysis. This is also the reason why double horizontal branches must be drilled according to our research.

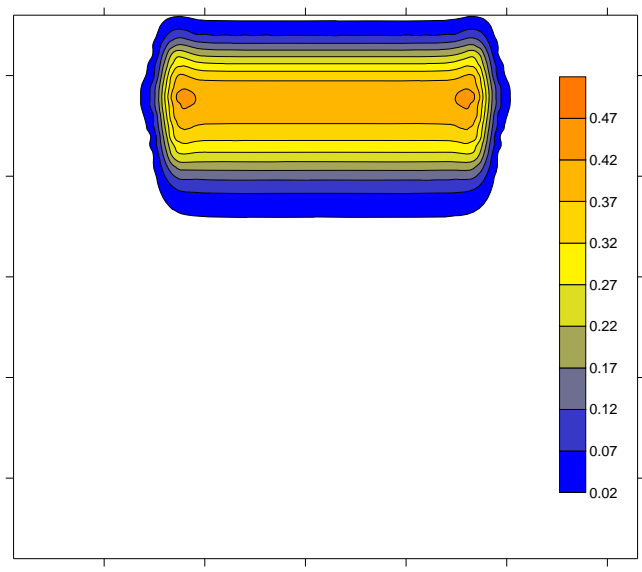

(a)

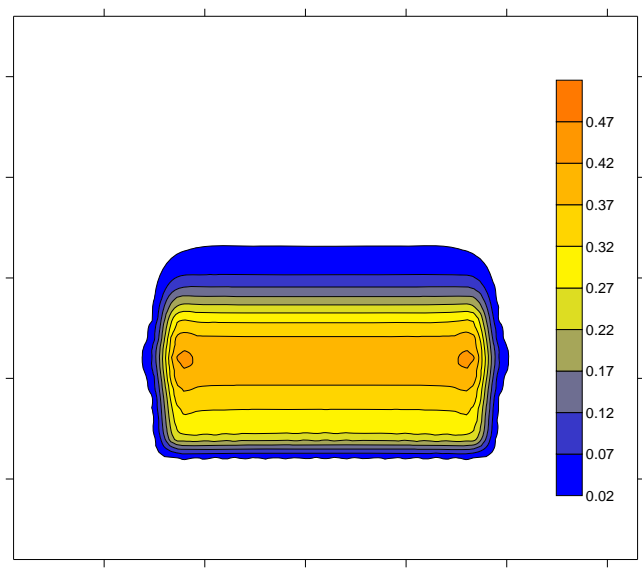

(c)
(3) Injecting nitrogen gas by the lower horizontal branch has no obvious effect either. This is because the apparent viscosity of nitrogen is quite low compared to that of oil in this simulation. When injected, nitrogen will flow to the upper part of the reservoir at a fast speed under the pressure drawdown caused by production. So when the upper production branch is open again, nitrogen will be produced and water

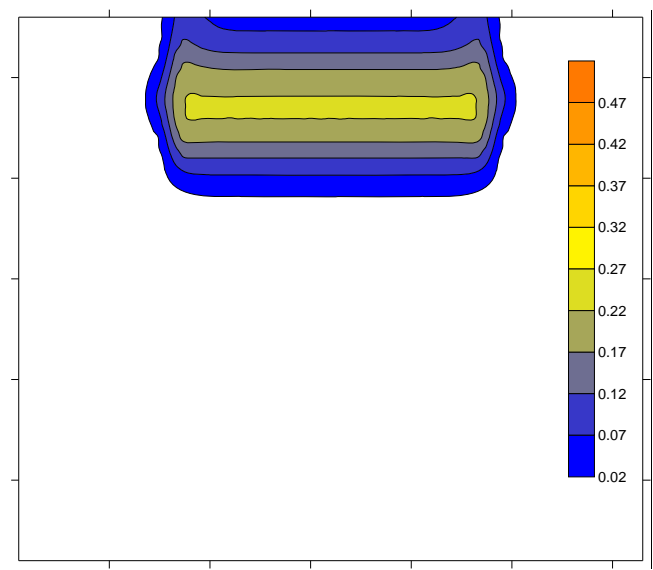

(b)

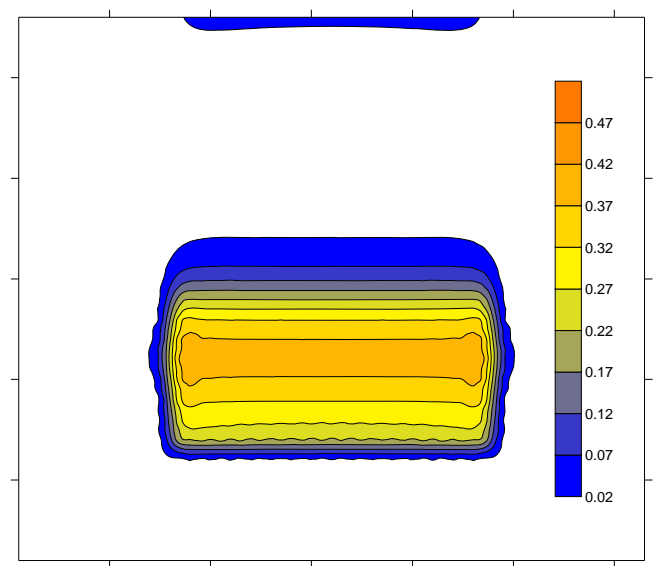

(d)

Fig. (5). Gas saturation distribution (a) when gas is injected for 20 days by IFUB (b) when produced for 30 days after foam injection by IFUB (c) when gas is injected for 20 days by IFLB (d) when produced for 30 days after foam injection by IFLB. 
cresting will reach the level before nitrogen injection in short period.

\section{THE PERFORMANCE OF IFLB IN HETERO- GENEOUS RESERVOIRS}

\subsection{Characterization of Heterogeneity and Simulations}

Impermeable shale barriers can have a great effect on water cresting. Previous simulation studies have shown that in bottom water reservoirs, the barrier helped increase oil recovery by delaying water breakthrough time and decreasing water cut $[13,14]$. In this paper, reservoir heterogeneity is introduced by including randomlydistributed thin shale. For laterally-oriented thin shale, it is reasonable to assume that the occurrence of shale in sand only reduces the vertical permeability to a relatively low value but has no effect on horizontal permeability. So, $0.001 \mathrm{mD}$ is applied to the vertical permeability of the shaly sand [18]. The stochastic distribution of shaly sand is represented based on a geostatistical method, sequential indicator simulation. For the simulated model, shaly sand content and its correlation length are the two key parameters which have great effects on the distribution and continuity of the shaly sand. Fig. (6) shows one of the realizations corresponding to shaly sand content equals to $50 \%$ and correlation length equals to $20 \mathrm{~m}$. It is mentionable that the stochastic simulation is only applied to the oil zone, which means water zone has no shaly sand.

IFLB is performed on numerical models that have different shale contents and correlation lengths. Shale contents are selected as $10 \%, 30 \%$ and $50 \%$ and correlation lengths are selected as $20 \mathrm{~m}, 40 \mathrm{~m}, 80 \mathrm{~m}$, and $160 \mathrm{~m}$ respectively. For each combination of shale content and correlation length, three stochastic models are built to conduct the simulation. Also, the development style BWF without any agent injected is performed for comparison. Incremental oil productions (IOPs) which are taken as the indicators to evaluate the effectiveness of IFLB for all kinds of combinations are listed in Table 2.

From Table 2, we can conclude that when shale content is low (i.e. 10\%), a good performance can be achieved no matter what correlation length is. Along with the increase of shale content, it is more likely to get a bad performance if the shale continuity is high too. The smallest IOP is obtained for the model whose shale content and correlation length are $50 \%$ and $80 \mathrm{~m}$, respectively. It is mentionable that the performances of IFLB may differ greatly even for realizations that have the same shale content and correlation length. Taking realizations with $30 \%$ shale content and $160 \mathrm{~m}$ correlation length for example, IOP for the third realization is $1.3586 \times 10^{4} \mathrm{~m}^{3}$, while that for the first realization is only $0.3568 \times 10^{4} \mathrm{~m}^{3}$. In order to get the key parameter that affects the performance of IFLB, both cases are selected for further analysis.

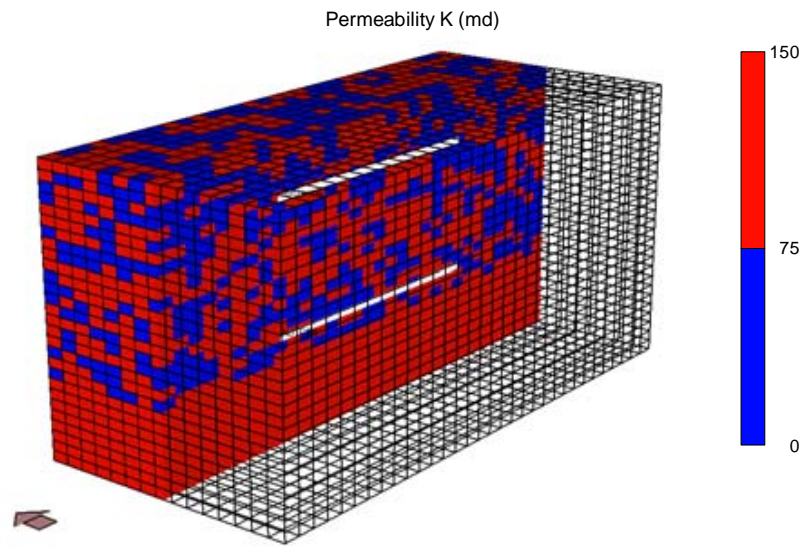

Fig. (6). Numerical grids for simulation. A representative $50 \%$ shale distribution is illustrated.

Fig. (7) illustrates the distributions of vertical permeability and gas saturation on the last day in simulation for the first and third realizations, respectively. From this figure, we can see that for the first realization, most of the foams are injected into the water zone due to the blocking of the upper shale; while for the third realization, foams are mostly injected to the pay zone. Meanwhile due to the high viscosity of foam and pressure gradient caused by production of the upper horizontal well, foam can't spread to a large area in the horizontal plane. In other words, foams are nearly injected in this single vertical layer. So it is reasonable to assume that the geological condition of this vertical layer can have a great effect on the performance of IFLB. In order to get a more comprehensive understanding about IFLB, the definition 'below well region' (BWR) is put forward and further simulation results are compared.

\subsection{Below Well Region-BWR}

The boundary of BWR is shown in Fig. (8) as a green rectangle. BWR has $225\left(15^{*} 1 * 15\right)$ blocks and occupies 2.34 percent of the total number of blocks in the pay zone. In order to examine the importance of BWR, two groups of realizations are used to simulate the performances of IFLB. For realizations in each group, shale distribution of BWR is

Table 2. Incremental Oil Production $\left(\times 10^{4} \mathrm{~m}^{3}\right)$ for Each Combination of Shale Content and Correlation Length

\begin{tabular}{|c|c|c|c|c|c|c|c|c|c|}
\hline \multirow{2}{*}{ Correlation Length } & \multicolumn{9}{|c|}{ Shale Content } \\
\hline & No.1 & No.2 & No.3 & No.1 & No.2 & No.3 & No.1 & No.2 & No.3 \\
\hline $20 \mathrm{~m}$ & 1.4217 & 1.2950 & 1.2875 & 1.3455 & 1.1667 & 1.3527 & 1.3531 & 1.4670 & 0.5358 \\
\hline $40 \mathrm{~m}$ & 1.4278 & 1.4867 & 1.4613 & 1.1664 & 1.3863 & 1.6155 & 1.2031 & 0.6432 & 0.1552 \\
\hline $160 \mathrm{~m}$ & 1.2132 & 1.4857 & 0.8084 & 0.3568 & 0.5630 & 1.3586 & 0.1978 & 0.1532 & 0.1558 \\
\hline
\end{tabular}




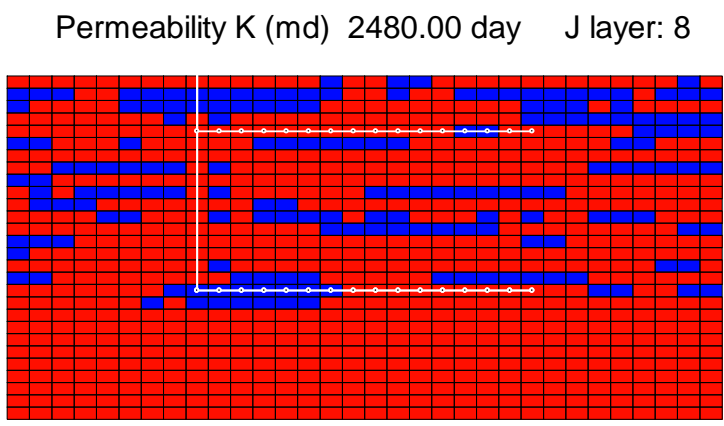

(a)

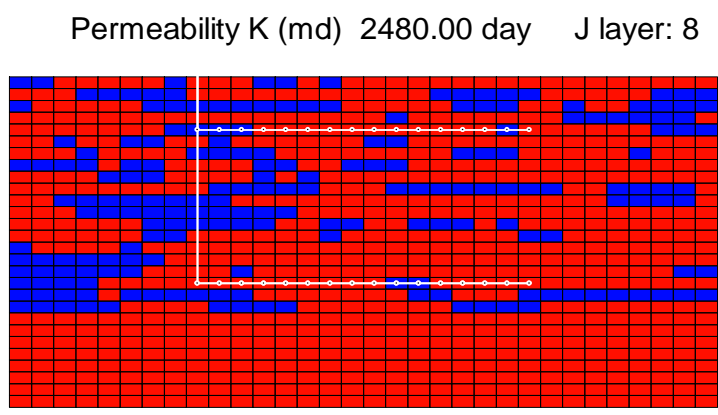

(c)
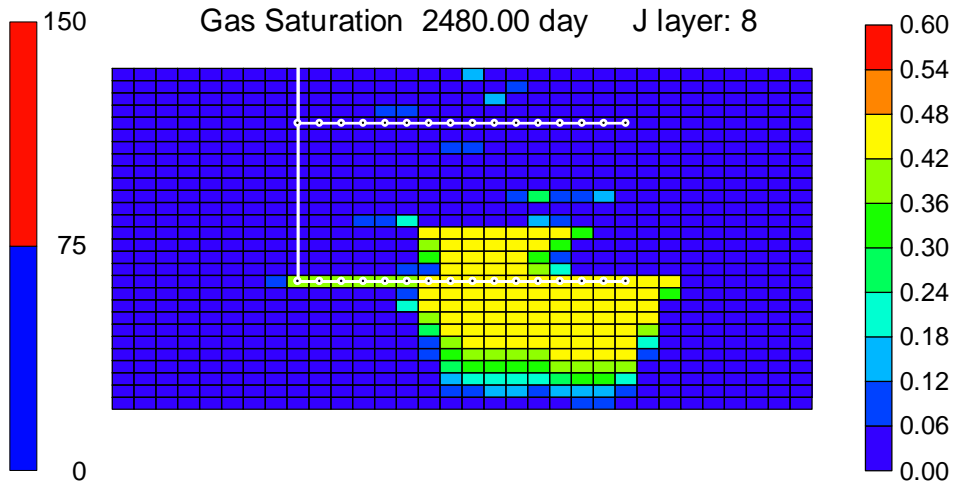

(b)
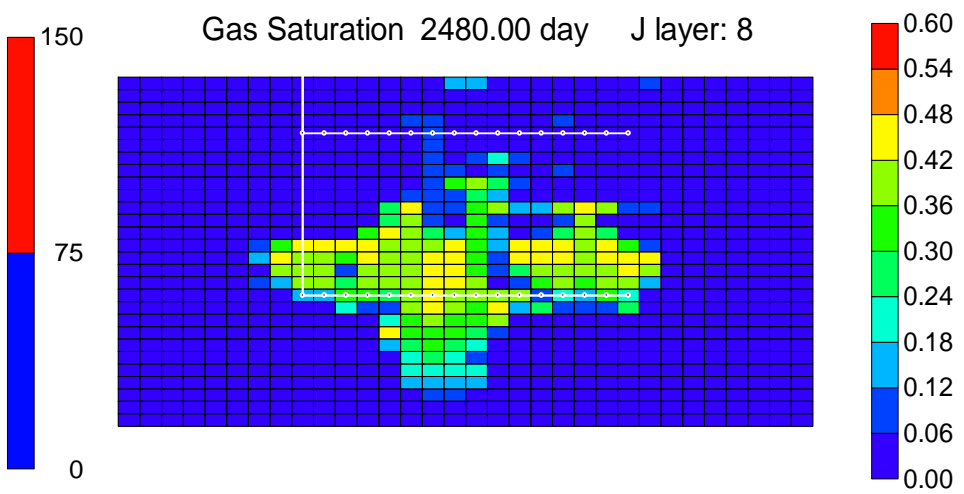

(d)

Fig. (7). Distributions of vertical permeability and gas saturation at $2480 \mathrm{~d}$ for the first and third realizations respectively. (a) and (b) are for the first realization; (c) and (d) are for the third realization.

fixed and the rest region (RR) is simulated with different combinations of shale contents and correlation lengths by sequential indicator simulation. Shale contents and correlation lengths of BWR for group 1 and group 2 are set to $10 \%, 50 \%, 20 \mathrm{~m}$ and $160 \mathrm{~m}$ respectively. Fig. (8) shows two realizations with same BWR but different RR in group 1. In addition, three equally probable realizations are built for each combination of shale content and correlation length.

IOPs for all realizations in group 1 and group 2 are listed in Tables 3 and $\mathbf{4}$ respectively. As expected, geological condition of BWR has a significant effect on the performance of IFLB. IOPs for realizations of group 1 are much bigger than that of group 2. Further analysis shows that if shale content and continuity are low for BWR, a good performance can be obtained even for realizations in which shale content and correlation length are both high for RR. This is because no matter what combination of shale content and correlation length is, BWR is still the main water channeling path due to the good geological condition of BWR and after foam injection, the following invasion bottom water will encounter a great resistance considering the strong blockage formed in BWR. While regarding to

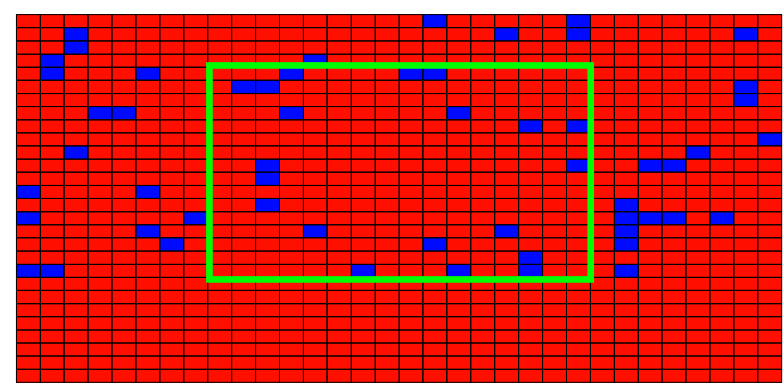

(a)

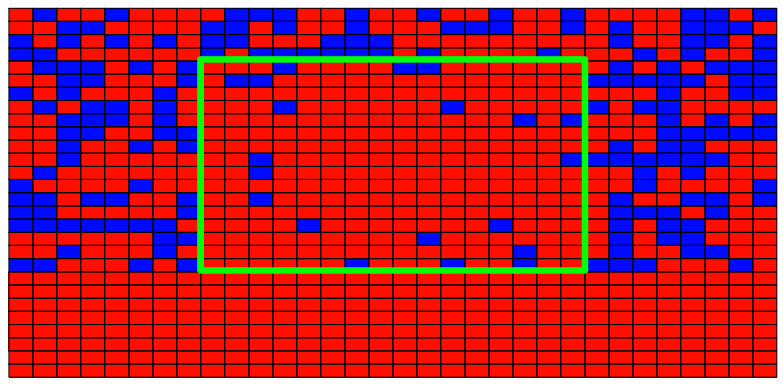

(b)

Fig. (8). Numerical grids in which shale contents of RR are (a) $10 \%$ (b) $50 \%$. 
Table 3. IOPs $\left(\times 10^{4} \mathrm{~m}^{3}\right)$ for Realizations in Group 1

\begin{tabular}{|c|c|c|c|c|c|c|c|c|c|}
\hline \multirow{3}{*}{$\begin{array}{l}\text { Correlation } \\
\text { Length }\end{array}$} & \multicolumn{9}{|c|}{ Shale Content } \\
\hline & \multicolumn{3}{|c|}{$10 \%$} & \multicolumn{3}{|c|}{$30 \%$} & \multicolumn{3}{|c|}{$50 \%$} \\
\hline & No.1 & No.2 & No.3 & No.1 & No.2 & No.3 & No.1 & No.2 & No.3 \\
\hline $20 \mathrm{~m}$ & 1.4557 & 1.4887 & 1.7258 & 1.7258 & 1.6863 & 1.7823 & 1.3007 & 1.1021 & 1.3869 \\
\hline $40 \mathrm{~m}$ & 1.5291 & 1.46892 & 1.4879 & 1.6549 & 1.6537 & 1.6908 & 1.2800 & 1.0597 & 1.3276 \\
\hline $80 \mathrm{~m}$ & 1.5185 & 1.3729 & 1.3819 & 1.5636 & 1.6305 & 1.5932 & 1.1065 & 0.9487 & 1.1247 \\
\hline $160 \mathrm{~m}$ & 1.4421 & 1.4356 & 1.3328 & 1.5331 & 1.3657 & 1.7291 & 1.0149 & 1.0106 & 1.0645 \\
\hline
\end{tabular}

Table 4. IOPs $\left(\times 10^{4} \mathrm{~m}^{3}\right)$ for Realizations in Group 2

\begin{tabular}{|c|c|c|c|c|c|c|c|c|c|}
\hline \multirow{3}{*}{$\begin{array}{l}\text { Correlation } \\
\text { Length }\end{array}$} & \multicolumn{9}{|c|}{ Shale Content } \\
\hline & \multicolumn{3}{|c|}{$10 \%$} & \multicolumn{3}{|c|}{$30 \%$} & \multicolumn{3}{|c|}{$50 \%$} \\
\hline & No.1 & No.2 & No.3 & No.1 & No.2 & No.3 & No.1 & No.2 & No.3 \\
\hline $20 \mathrm{~m}$ & 0.8790 & 0.9488 & 0.9336 & 0.5697 & 0.8311 & 0.7580 & 0.6138 & 0.3213 & $0 . .3309$ \\
\hline $40 \mathrm{~m}$ & 0.7987 & 0.8705 & 0.8573 & 0.3685 & 0.9233 & 0.6857 & 0.4104 & 0.7587 & 0.7598 \\
\hline $80 \mathrm{~m}$ & 0.8208 & 0.7642 & 0.9231 & 0.4680 & 0.1029 & 0.3494 & 0.5104 & 0.3108 & 0.1989 \\
\hline $160 \mathrm{~m}$ & 0.7605 & 0.6183 & 0.6027 & 0.6027 & 0.3686 & 0.3472 & 0.6290 & 0.9494 & 0.9613 \\
\hline
\end{tabular}

group 2, variations in performance still exist for different realizations which have the same shale content and continuity. This is because a portion of foam will flow to adjacent vertical layers due to the high blockage of BWR, so geological conditions of RR will have some effects on the performance of IFLB. However, these variations are greatly suppressed compared to prior simulation results and there is no doubt that the performance of IFLB will signficantly decrease if the geological condition of BWR is not good.

\section{CONCLUSIONS}

This work presents a numerical investigation of IFLB. Different development styles including IFLB, INLB, IFUB and BWF are compared and detailed analysis about IFUB is studied on homogeneous models. The effect of the reservoir heterogeneity on the performance of IFUB has also been considered. The following conclusions are derived:

1. IFLB is the best development style compared to INLB, IFUB and BWF. After foam injection, a strong blockage can form around the lower injection branch and the following bottom water shows a trend of bypassing the foam zone due to this blockage which will lead to higher sweep efficiency. Meanwhile, part of nitrogen gas released by foam decay can form a secondary gas cap on the top of the reservoir. This gas cap will supplement the pressure drawdown and flood oil in the upper layer downward to the production well which can also enhance oil recovery.

2. IFUB can't yield a big increase of oil production. When producing, high pressure gradient of near well region and oil flooded by bottom water will greatly affect the stability of foam and the released nitrogen gas will be produced immediately which will lead to a failed anti-water-cresting operation.
3. For heterogeneous reservoirs, the geological condition of BWR has a great effect on the performance of IFLB. If shale content of BWR is low, a good performance can be obtained with any combination of shale content and continuity for RR. On the contrary, if shale content and continuity of BWR are high, the performance of IFLB will significantly decrease. Though variations of IOPs still occur, it is highly depressed due to the fixation of BWR.

For this work, foam is chosen as the injecting agent allowing for its strong blockage to water. It is mentionable that foam stability is also related to temperature, pressure, water salinity and so on. So, comprehensive experimental tests should be conducted to evaluate the foam property before using IFLB. Moreover, high-viscosity polymer can also have a good blocking ability as illustrated in many publications. Further studies are ongoing to supplement present study results.

\section{ACKNOWLEDGEMENT}

Declared none.

\section{CONFLICT OF INTEREST}

The authors confirm that this article content has no conflicts of interest.

\section{ABBREVIATIONS}

IFLB = Injecting foam by the lower horizontal branch

IFUP = Injecting foam by the upper horizontal branch

INLB = Injecting nitrogen gas by the lower horizontal branch

$\mathrm{BWF}=$ Bottom water flooding

$\mathrm{BWR}=$ Below well region

$\mathrm{RR}=$ The rest region 


\section{REFERENCES}

[1] Sherrard, D.W.; Brice, B.W.; MacDonald, D.G. Application of horizontal wells at Prudhoe Bay. J. Pet. Technol., 1987, 39(11), 1417-1425.

[2] Target, P.L.; Unocal Netherlands B.V. The Haven Oil Field: Development of a tiny marginal field with horizontal wells. J. Pet. Technol., 1992, 44(4), 496-501.

[3] Permadi, P.; Lee, R.L.; Kartoatmodjo, R.S.T. Behavior of Water Cresting Under Horizontal Wells. In: SPE Annual Technical Conference and Exhibition; 22-25 Oct; Texas: USA, 1995.

[4] Xiong, Y.M.; Luo, D.H.; Tang, H.X. New-type horizontal well completion method of delaying and controlling bottom water coning. J. Southwest. Pet. Univ., 2009, 31(1), 103-106.

[5] Dai, C.L.; Zhao, F.L.; and Li, Y.L. Control technology for bottom water coning in horizontal well of offshore oilfield. Acta Pet. Sin., 2005, 26(4), 69-72.

[6] Singhal, A.K. Water and gas coning/cresting a technology overview. J. Can. Pet. Technol., 1996, 35(4), 1-6.

[7] Zhou, D.Y.; Jiang, T.W.; Feng, J.L. Waterflooding performance and pattern in horizontal well with bottom water reservoir. Acta Pet. Sin., 2004, 25(6), 73-77.

[8] Coffin; Philippe; Elf Aquitaine. Horizontal Well Evaluation After 12 Years. In: SPE Annual Technical Conference and Exhibition; 36 Oct 1993; Texas: USA, 1993.

[9] Ozkan, E.; Raghavan, R. Performance of horizontal wells subject to bottom water drive. SPE Reserv. Eng., 1990, 5(3), 375-383.
[10] Chaperon, I. Theoretical Study Of Coning Toward Horizontal And Vertical Wells In Anisotropic Formations: Subcritical And Critical Rates. In: SPE Annual Technical Conference and Exhibition: 5-8 Oct 1986; Louisiana: USA, 1986.

[11] Fan, Z.F. A study of critical rate of a horizontal well in a reservoir with bottom-water drive. Pet. Explor. Dev., 1994, 21(1), 65-70.

[12] Zhao, G.; Zhou, J.; Liu, X. An insight into development of bottom water reservoirs. J. Can. Pet. Technol., 2006, 45(4), 22-30.

[13] Zhang, P.; Wen, X.H.; Ge, L.Z. Existence Of Flow Barriers Improves Horizontal Well Production In Bottom Water Reservoirs. In:SPE Annual Technical Conference and Exhibition; 21-24 Sep 2008; Colorado: USA, 2008.

[14] Lien, S.C.; Haldorsen, H.H.; Morten Manner. Horizontal wells: still appealing in formations with discontinuous vertical permeability barriers? J. Pet. Technol., 1992, 44(12), 1364-1370.

[15] Barnes, A.L. The use of a viscous slug to improve waterflood efficiency in a reservoir partially invaded by bottom water. $J$. Pet.Technol., 1962, 24(10), 1147-1153.

[16] Islam, M.R.; Farouq Ali, S.M. Improving Waterflood Performance In Oil Reservoirs With Bottom Water. In: SPE Annual Technical Conference and Exhibition; 27-30 Sep 1987; Texas: USA, 1987.

[17] Pang, Z.-X.; Liu, H.-Q.; Liu, X.-L. Experiments on blocking ability of nitrogen foam and its application in anti-water-coning. Pet. Sci. Technol., 2010, 28(12), 1260-1276.

[18] Chen, Q.; Gerritsen, M.G.; Kovscek, A.R. Effects of reservoir heterogeneities on the steam-assisted gravity-drainage process. SPE Reserv. Eval. Eng., 2008, 11(5), 921-932.

(C) Yong-Ge et al.; Licensee Bentham Open.

This is an open access article licensed under the terms of the Creative Commons Attribution Non-Commercial License (http://creativecommons.org/licenses/by$\mathrm{nc} / 3.0 /$ ) which permits unrestricted, non-commercial use, distribution and reproduction in any medium, provided the work is properly cited. 